\title{
Uso E Desenvolvimento De Tecnologias Digitais Da Informação E Comunicação Na Formação De Licenciandos
}

\author{
Use And Development Of Information And Communication Digital \\ Technologies In The Undergraduates Formation \\ Uso Y Desarrollo De Tecnologías Digitales De Información Y \\ Comunicación En La Formación De Alumnos De Licenciamiento
}

LUCIANA DE LIMA ${ }^{1}$, ROBSON CARLOS LOUREIRO², BRENA COLLYER DE AGUIAR ${ }^{3}$

${ }^{1}$ Universidade Federal do Ceará

2 Universidade Federal do Ceará

${ }^{3}$ Universidade de Sussex

\begin{abstract}
RESUMO: O objetivo do presente trabalho é analisar como os participantes de grupos interdisciplinares, estudantes de Instituição Pública de Ensino Superior (IPES) integram as Tecnologias Digitais da Informação e Comunicação (TDICs) e Docência ao desenvolver Materiais Autorais Digitais Educacionais (MADEs). Considerando-se a subutilização das TDICs no contexto da formação de licenciandos, a pesquisa qualitativa se caracteriza como Estudo de Caso realizada com 30 participantes da disciplina Tecnodocência no primeiro semestre de 2019. A análise de dados utiliza a triangulação metodológica ao comparar os resultados do questionário de sondagem, dos roteiros dos Materiais Autorais desenvolvidos e do referencial teórico. Os participantes saíram da compreensão de docência vinculada à centralização do saber no professor para outra compreensão que envolve os alunos em trabalho colaborativo.
\end{abstract}

TECNOLOGIA DIGITAL DA INFORMAÇÃO E COMUNICAÇÃO. FORMAÇÃO DE PROFESSORES. LICENCIATURA. INTERDISCIPLINAR.

\begin{abstract}
The objective of the present work is to analyze how the participants of interdisciplinary groups, students of Public Institutions of Higher Education (PIHE) integrate the Information and Communication Digital Technologies (ICDT) and Teaching when developing Digital Authorial Educational Materials (DAEM). Select an underutilization of TDICs in the context of undergraduates training, qualitative research is carried out as a Case Study with 30 participants in the discipline Technoteaching in the first semester of 2019. Data analysis uses the methodological triangulation when comparing the results of the survey questionnaire, the developed $M A D E$ scripts and, the theoretical referential. Participants moved from the understanding of teaching linked to the centralization of knowledge in the teacher to another understanding that involves students in collaborative work.
\end{abstract}

INFORMATION AND COMMUNICATION DIGITAL TECHNOLOGY. TEACHER FORMATION. UNDERGRADUATE. INTERDISCIPLINARY.

Os autores cedem à Revista Internacional Educon os direitos de primeira publicação do presente artigo. Aplicam-se os termos de uma licença Creative Commons Atribuição 4.0 Internacional (CC BY 4.0), que permite o uso irrestrito, a distribuição e a reprodução em qualquer meio desde que a publicaşão original seja corretamente citada. 


\begin{abstract}
RESU'MEN: El objetivo del presente trabajo es analizar cómo los participantes de grupos interdisciplinarios, estudiantes de Instituciones Públicas de Educación Superior (IPES) integran las Tecnologías Digitales de Información y Comunicación (TDIC) y la Enseñanza al desarrollar Materiales Autorales Digitales Educativos (MADEs). Teniendo en cuenta la subutilización de las TDIC en el contexto de la formación de graduandos, la investigación cualitativa se caracteriza como un estudio de caso realizado con 30 participantes en la disciplina Tecnoenseñanza en el primer semestre de 2019. El análisis de datos utiliza la triangulación metodológica al comparar los resultados del cuestionario de la encuesta, los guiones de los $M A D E$ desarrollados y el marco teórico. Los participantes pasaron de la comprensión de la enseñanza vinculada a la centralización del conocimiento en el maestro a otra comprensión que involucra a los estudiantes en el trabajo colaborativo.

\section{TECNOLOGÍA DIGITAL DE INFORMACIÓN Y COMUNICACIÓN. FORMACIÓN DE PROFESORES. LICENCIAMIENTO.} INTERDISCIPLINARIDAD.
\end{abstract}

\title{
Introdução
}

As relações interpessoais têm se alterado com fenômenos vinculados à ampliação da comunicação com o advento da internet. Apesar de a escola e sua comunidade estarem imersas em uma sociedade imbricada de conceitos da cibercultura, pouco contemplam o uso das Tecnologias Digitais da Informação e Comunicação (TDICs) em suas atividades voltadas para o ensino, a aprendizagem e a avaliação. A integração entre o pensar crítico sobre as TDICs se torna imprescindível para a sociedade atual, como afirma Kerchove (2009), bem como para a formação do professor. Segundo Lemos (2013), o fenômeno da penetração da tecnologia digital na sociedade, expande-se para o meio educacional como hegemônico, mas não um fenômeno de maioria.

Quando se trata de prática docente, Coll (2009) afirma que o uso das TDICs se torna coerente com a compreensão que os professores apresentam sobre ensino. A transmissão de conteúdos quando realizada corriqueiramente, também o é diante do uso das TDICs. Atividades de exploração e criação quando inseridas no contexto comum da docência, também o são quando fazem uso das TDICs. A transformação pedagógica que se espera do professor não acontece, segundo o autor, simplesmente com a inserção das TDICs no ambiente escolar, mantém-se a prática vigente.

Loureiro, Lima e Soares (2014) corroboram os resultados de Coll (2009) ao pesquisarem a utilização das TDICs por professores de Ensino Superior. Apesar de os professores se preocuparem com as novidades tecnológicas e buscarem sua utilização na prática docente, ainda insistem na exposição de conteúdos, mesmo diante de diferentes possibilidades de mudanças metodológicas. Denota-se, dessa forma, a fragilidade do processo de formação docente para o uso das TDICs.

A inserção das TDICs de forma crítica na formação docente pode ser realizada em diferentes formatos e propostas. O conceito de Tecnodocência vem, nesse sentido, agregar ideias que possibilitem o rompimento com o que comumente se pensa sobre a conexão entre tecnologia digital e docência. Define-se Tecnodocência, portanto, como a integração entre Docência e TDICs com base epistemológica nos modelos interdisciplinares e transdisciplinares por meio da utilização dos conhecimentos prévios do aprendiz para o desenvolvimento de uma reflexão crítica sobre os processos de ensino, aprendizagem e avaliação (LIMA; LOUREIRO, 2019).

Um dos pilares que compõe o conceito de Tecnodocência é o da Interdisciplinaridade a partir dos pressupostos teóricos de Japiassu (2006). Contempla-se a necessidade de trocas conceituais e aprendizagens mútuas entre os especialistas de diferentes disciplinas a partir do compartilhamento de conhecimentos e discussões conjuntas. Outro pilar se encontra no conceito de Aprendizagem Significativa desenvolvido por Ausubel, Novak e Hanesian (1980). Considera-se necessário utilizar os 
conhecimentos prévios do aprendiz de forma substantiva e não-arbitrária para haver o desenvolvimento de sentidos e significados aos conceitos que podem ser ancorados em sua estrutura cognitiva.

Em pesquisas desenvolvidas sobre o tema, as TDICs auxiliam no desenvolvimento de atividades interdisciplinares, permitindo o uso de metodologias e didáticas que favoreçam a aprendizagem de maneira não convencional a partir da interação entre os participantes, da troca de informações e da integração entre os diferentes saberes. De acordo com a problemática apresentada e considerando-se a necessidade de integração entre TDICs e docência em contexto interdisciplinar na formação de licenciandos e bacharelandos, pergunta-se: como a utilização dos conhecimentos prévios de grupos interdisciplinares na construção do conceito de Tecnodocência influencia na forma como buscam integrar TDICs e Docência?

Sendo assim, a Universidade Federal do Ceará (UFC) implantou a partir de 2015, em parceria com escolas públicas, a disciplina denominada Tecnodocência, atendendo aos licenciandos de catorze áreas específicas do conhecimento e bacharelandos do curso de Sistemas e Mídias Digitais que trabalham conjuntamente para o desenvolvimento de Materiais Autorais Digitais Educacionais (MADEs). Os discentes têm, portanto, a oportunidade de criar seus próprios materiais digitais pensando na aplicabilidade na prática docente diante de uma experiência interdisciplinar. Os MADEs são definidos, portanto, como todo e qualquer material educacional "desenvolvido por um aprendiz utilizando um equipamento digital conectado ou não à internet com criação, planejamento, execução, reflexão e avaliação desenvolvidos pelo próprio aprendiz individualmente ou em grupo [...]" (LIMA; LOUREIRO, 2016a, p. 630).

A pesquisa relatada nesse contexto tem por objetivo analisar como os participantes de grupos interdisciplinares, estudantes da UFC do primeiro semestre de 2019, integram TDICs e Docência ao desenvolver Materiais Autorais Digitais Educacionais (MADEs). A metodologia utilizada foi o Estudo de Caso com coleta de dados realizada em duas fases por meio da investigação dos conhecimentos prévios dos participantes sobre docência e tecnodocência, e, sobre como desenvolvem os MADEs. A análise emprega como estratégia a triangulação metodológica, utilizando-se de questionário de sondagem, do roteiro dos MADEs desenvolvidos pelos licenciandos e do referencial teórico, com estratégias pautadas na Análise Textual Discursiva (MORAES; GALIAZZI, 2016).

Os sujeitos da pesquisa saíram de uma compreensão de docência vinculada à centralização do saber no professor, atuando de forma isolada em sala de aula, para outra compreensão que valoriza o desenvolvimento de um trabalho colaborativo entre alunos e professores.

\section{As Tecnologias Digitais da Informação e Comunicação na Formação de Professores}

As propostas de Formação de Professores que contemplam a integração entre as TDICs e os aspectos educacionais são apresentadas de formas variadas por meio de pesquisas e políticas oriundas de países que consideram o uso da tecnologia digital como uma forma de comunicação global, social e cultural. A inserção do uso das TDICs vincula-se ao processo de desenvolvimento profissional, pensada também para as formações iniciais.

A proposta da Unesco (2002) se apresenta em quatro estágios. Inicialmente, há a necessidade do desenvolvimento de habilidades e conhecimentos dos professores sobre os aspectos tecnológicos. Realizar tarefas pessoais e profissionais utilizando os recursos da internet e de softwares corriqueiros auxiliam na compreensão das possibilidades relacionadas ao uso da tecnologia digital.

Em um segundo momento, é necessário que o professor aprenda a aplicar as TDICs para aprimorar a aprendizagem de seus alunos e sua própria aprendizagem. É somente após esses dois passos iniciais que os professores contemplam a transformação pedagógica. Deverão aprender a integrar as características da tecnologia digital aos objetivos didático-metodológicos diante de um trabalho 
colaborativo pautado na construção do conhecimento. Porém, é preciso que os resultados obtidos sejam compartilhados, discutidos e refletidos de forma colaborativa com seus pares, colegas e especialistas, para que as mudanças sejam efetivadas e incorporadas ao fazer pedagógico (ALMEIDA; VALENTE, 2011).

Para Ricardo (2007), a ideia de se trabalhar com tecnologia no contexto educacional é possível quando se pensa a tecnologia como um produto a ser desenvolvido por alunos e professores. Oriunda dos pressupostos do Movimento CTSA (Ciência, Tecnologia, Sociedade e Ambiente) que se baseiam em dois pensamentos básicos: os saberes científicos e tecnológicos levam a humanidade a um futuro melhor; estes mesmos saberes devem ser orientados para a ação a partir da análise social, histórica, política e econômica, o grande desafio ao integrar a tecnologia ao contexto educacional é a superação da visão privilegiada que a tecnologia apresenta em relação à concepção social de ciência. $O$ autor apresenta, para a formação do professor, uma proposta que possibilite a alfabetização tecnológica dos alunos por meio da reorientação dos saberes ensinados, da superação das dificuldades dos professores em abstrair suas experiências tornando os saberes práticos menos discursivos e de mudanças na rotina das ações de professores e alunos impostas pela escola.

Ao se trabalhar no contexto das TDICs, esse objetivo é alcançado quando são possibilitados recursos que permitam a exploração, a investigação e a descoberta. De acordo com Baranauskas, Martins e Valente (2013), os sistemas tecnológicos a serem utilizados devem ser análogos aos sistemas físicos. Sem ensinar ou instruir, permitem que o aprendiz, seja ele aluno ou professor, atue como cientista aplicando princípios a um sistema de experimentação. Ambientes que permitem o desenvolvimento de simulações de situações científicas, de modelos, de programas básicos e pequenos softwares de autoria são exemplos de instrumentos que podem auxiliar o licenciando a assimilar os conceitos científicos integrados aos conhecimentos tecnológicos de forma reflexiva e crítica.

Os autores mencionados anteriormente ressaltam ainda que ao se trabalhar dentro dessa perspectiva construcionista de aprendizagem alguns aspectos relevantes se evidenciam. A aprendizagem se torna efetiva por meio da construção do conhecimento, pela liberdade de ação e pela reflexão a partir dos erros cometidos no processo. Os feedbacks enviados pelo sistema em uso, considerados importantes para o processo de aprendizagem, são gerados como função de escolhas e de ações do aprendiz dentro do sistema. O computador deve ser utilizado como uma máquina a ser ensinada. A partir de suas premissas, o aprendiz deve inserir seu conjunto de ideias para obter a resposta de suas próprias ações (PAPERT, 2008).

A visão internacional para o uso das TDICs na Formação de Professores não se diferencia daquela que se almeja nas propostas brasileiras. Estudos realizados no Quebec sobre o referencial das competências profissionais para os futuros professores ressaltam que a apropriação das TDICs para o planejamento, a condução das aulas e a gestão do ensino são imprescindíveis para a prática docente. $\mathrm{O}$ professor deve saber se comunicar com a ajuda das TDICs, bem como planejar e ensinar com elas, estimulando seus alunos a utilizarem-nas para aprenderem melhor (KARSENTI; VELLENEUVE; RABY, 2008).

Segundo Ramos e Struchiner (2009) para que o aluno se envolva em processos de investigação que permitem a ampliação de sua aprendizagem é necessário que colete diferentes recursos de informação, preveja os resultados por meio de experimentações, discuta esses resultados, avalie as informações coletadas e divulgue os resultados obtidos. Para isso, é necessário que o professor saiba trabalhar esses aspectos com fundamentação metodológica, possibilitando, dentro de ambientes tecnológicos uma descentralização, destemporalização e desterritorialização do saber que passa a ser compartilhado entre todos, professor e alunos. Por isso, a necessidade de formações iniciais e continuadas que permitam ao professor uma conscientização do uso das TDICs disponíveis na contemporaneidade em situações de ensino, aprendizagem e avaliação que permitam a criação e a reflexão de todos os envolvidos em prol de maior engajamento e significado que podem garantir uma aprendizagem de alunos e professores com melhor qualidade (LIMA; LOUREIRO, 2019). 


\section{Metodologia}

A pesquisa de caráter qualitativo utiliza como metodologia o Estudo de Caso. Essa escolha se justifica pelo fato de investigar um fenômeno contemporâneo, de considerar a não exigência de controle sobre os eventos comportamentais e de utilizar fontes de evidências diretas na compreensão dos fenômenos estudados (YIN, 2010).

São apresentados os resultados da pesquisa oriundos do projeto Universal CNPq 2016, compondo um dos trabalhos desenvolvidos pelo Grupo de Pesquisa Tecnodocência. Vale ressaltar que os participantes da pesquisa assinaram o Termo de Consentimento Livre e Esclarecido, uma vez que o projeto foi aprovado pelo Comitê de Ética em Pesquisa da UFC. A unidade de análise é composta por cinco (5) grupos interdisciplinares de estudantes formados por um máximo de quatro (4) integrantes, oriundos de diferentes cursos de Licenciatura da Universidade Federal do Ceará, participantes da disciplina Tecnodocência no primeiro semestre de 2019, ofertada, com 30 vagas.

A turma é composta por trinta (30) estudantes, vinte (20) homens e dez (10) mulheres. São oriundos das Licenciaturas em Ciências Biológicas, Física, Música, História, Letras, Matemática, Pedagogia e Química. A faixa etária média do grupo é de vinte e quatro (24) anos. Dois (2) integrantes estão cursando os primeiros semestres de seus respectivos cursos, cinco (5) integrantes estão nos semestres intermediários e vinte e três (23) estão cursando os últimos semestres. Todos utilizam computador e internet todos os dias. Navegam principalmente pelas redes sociais, por sites sobre profissão, trabalhos acadêmicos, jogos e entretenimento.

A disciplina Tecnodocência tem como objetivo formar estudantes que queiram atuar como docentes diante da utilização de uma proposta metodológica interdisciplinar integrada às TDICs pautada no estudo teórico-prático da Teoria da Aprendizagem Significativa de Ausubel, da Teoria de Fluxo, da Filosofia da Diferença, dos conceitos de Interdisciplinaridade e do Construcionismo. Possibilita a valorização e a utilização dos conhecimentos prévios dos participantes, a construção do engajamento e do significado dos conceitos e o desenvolvimento do pensamento crítico-reflexivo sobre a ação da prática docente.

A pesquisa está concebida em três (3) etapas: planejamento, coleta e análise de dados. Na primeira, são preparadas as estratégias, os protocolos, os instrumentos e a política de armazenamento de informações na coleta e na análise dos dados. Além disso, são preparados os equipamentos para o desenvolvimento dos MADEs. Na segunda etapa, é realizada a coleta de dados em duas (2) fases por meio da investigação: dos conhecimentos prévios que os licenciandos apresentam sobre docência e tecnodocência; e, sobre a forma como os licenciandos concebem, desenvolvem e propõem os MADEs. Ressalta-se a utilização de dois (2) protocolos de coleta de dados.

$\mathrm{Na}$ primeira fase, os licenciandos respondem um questionário, disponibilizado em nuvem, contendo informações pessoais e conceituais. Na segunda fase, iniciam discussões e compreensões teóricas sobre os conteúdos de estudo. Os grupos interdisciplinares são formados e cada um define seu tema, os conteúdos envolvidos e os objetivos a serem alcançados para o desenvolvimento de um trabalho docente interdisciplinar. Elaboram roteiros de desenvolvimento dos MADEs, bem como, executam as ações necessárias para sua concretização diante da articulação dos conteúdos.

A análise de dados ocorre pela interpretação dos discursos utilizados pelos grupos interdisciplinares explícitos nos questionários de sondagem em comparação ao roteiro desenvolvido para a elaboração dos MADEs, a partir de referencial teórico determinado. Para isto, é utilizada uma triangulação metodológica, favorecendo a comparação das informações em diferentes instrumentos da pesquisa, a fim de verificar as convergências e divergências das interpretações de forma linear (STAKE, 2010). A análise de dados se subdivide em duas (2) categorias: compreensão dos aspectos vinculados à interdisciplinaridade; compreensão dos aspectos vinculados às tecnologias digitais.

Para auxiliar o processo, utilizaram-se os procedimentos propostos pela Análise Textual Discursiva (MORAES; GALIAZZI, 2016). Diante de um processo organizado para a compreensão do fenômeno 
estudado e a busca dos elementos emergentes da pesquisa, utilizou-se uma sequência recursiva composta por cinco (5) fases: unitarização, categorização, descrição, interpretação e argumentação.

$\mathrm{Na}$ fase da unitarização foram definidas as unidades de análise, com seleção e definição do corpus utilizado, iniciando-se a desmontagem dos textos. As unidades de análise foram codificadas e definidas, utilizando-se como base os aspectos emergentes das leituras e releituras dos textos selecionados. Posteriormente, as unidades foram reescritas com atribuição de um título, representando sua ideia central.

$\mathrm{Na}$ fase da categorização, agruparam-se elementos semelhantes, por meio da comparação das unidades de análise. Utilizou-se um método indutivo, construindo-se as categorias emergentes a partir das informações captadas do corpus. Neste momento inicial, as unidades de análise foram comparadas e agrupadas para atribuição de significado. Com isso, as categorias foram criadas, definidas e nomeadas.

$\mathrm{Na}$ fase da descrição apresentaram-se elementos emergentes dos textos analisados e representados pelas categorias construídas. Realizaram-se novas leituras e interpretação direta dos textos, com utilização de recortes produzidos pelos sujeitos da pesquisa. $\mathrm{Na}$ fase da interpretação desenvolveu-se uma leitura teórica dos fatos empíricos de forma profunda e complexa, estabelecendo-se uma relação entre as descrições interpretativas e os aspectos teóricos que compõem a pesquisa bibliográfica.

$\mathrm{Na}$ fase da argumentação apresentaram-se afirmações teóricas emergentes do processo de análise com a elaboração de um metatexto de caráter descritivo, formado por elementos introdutórios, pela produção de uma argumentação centralizadora que explica o todo a partir das relações dos argumentos produzidos para as categorias e por um fechamento que torne o texto o mais claro e preciso possível.

\section{Resultados e Discussão}

Os resultados são apresentados a partir das duas (2) fases da coleta de dados. Os grupos interdisciplinares pesquisados são intitulados de G1, G2, G3, G4 e G5 a fim de evitar dubiedade em relação à linguagem utilizada no texto.

\subsection{Conhecimentos Prévios sobre Docência e Tecnodocência}

O questionário de sondagem é composto por trinta (30) questões. Para análise dos conceitos de Docência e de Tecnodocência são utilizadas duas (2) perguntas: "O que é Docência?" e "O que é Tecnodocência?". Nenhum dos grupos citou o termo interdisciplinaridade na definição do conceito de Docência. No entanto, em relação ao termo Tecnodocência, apenas dois integrantes do G3 vincularam a relação entre docência e tecnologia com a ideia interdisciplinar de forma explícita: “Área interdisciplinar que mescla tecnologia e docência em prol de uma melhor educação" (G3); "É um método de ensinoaprendizagem-avaliação que se utiliza de tecnologias baseando-se no conceito de interdisciplinaridade no ato da docência" (G3). Apesar desse resultado, os licenciandos não fizeram menção ao fato de os professores trabalharem conjuntamente na prática docente. A ação docente parece ser única, específica de um professor e de sua área de saber, mesmo quando inserida no contexto das TDICs.

O ideário que os licenciandos trazem sobre Docência está marcado pela compreensão de atuação isolada do professor, caracterizando uma formação pautada na fragmentação dos saberes como afirma Tardif (2002), na separação entre teoria e prática como denuncia Charlot (2005) e na vivência de salas de aula regidas por apenas um professor, detentor de determinado conhecimento específico. Essas experiências formativas, bem como a exigência curricular das escolas de ter um professor atuando em uma única disciplina, atendendo a diferentes séries dentro de um espaço delimitado, fechado e com horário pré-determinado auxiliam na construção do que é ser professor, vinculado a um trabalho solista, individual e centralizado em seus próprios conhecimentos. 
Essa perspectiva recai ainda na construção de um conceito novo como a Tecnodocência que traz imbricada em sua definição a explicitação do trabalho do professor como sendo interdisciplinar ou transdisciplinar, portanto, descentralizado e pautado na parceria e aprendizagem mútua entre professores. Segundo Ausubel, Novak e Hanesian (1980), quando um conceito está ancorado em conceitos previamente consolidados na estrutura cognitiva do aprendiz torna-se bastante difícil concretizar a desvinculação conceitual. Para os licenciandos, é possível que desvincular a ideia de docência de uma proposta de ação isolada do professor, abrindo espaço para uma nova proposta de ação, o trabalho colaborativo entre professores, seja complexo e se encaixe no perfil citado pelos autores.

Em relação à definição de Docência, nenhum grupo explicitou a necessidade de utilização das tecnologias digitais. No entanto, ao definirem Tecnodocência, em todas as respostas, as tecnologias digitais se fizeram presentes. Para o G1, as tecnologias digitais podem ser utilizadas para a transmissão do conhecimento: "Assim como a docência é maneira planejada e capacitada de repassar conhecimentos através de diálogo, interação e dinâmicas, só que utiliza a tecnologia como ferramenta para que isso ocorra ou seja facilitado." (G1). Para o G2, as tecnologias digitais são utilizadas em prol do ensino: "É a utilização de tecnologias digitais para a mediação de conhecimentos." (G2). No caso do G3, as tecnologias digitais como ferramentas se conectam ao aspecto da aprendizagem do aluno: "É a utilização de ferramentas mais atuais, mais rápidas e que conversam melhor com os jovens, na intenção de melhorar o processo de aprendizagem." (G3). Para o G4, as tecnologias digitais se vinculam à ideia de melhoria do processo de ensino: "Utilizar-se de tecnologia para melhorar os processos de ensino" (G4). Para o G5, a ideia das tecnologias se relaciona a sua utilidade para o ensino: "O ensino ou ato de ensinar que utiliza as tecnologias como ferramentas da educação" (G5).

Segundo Coll (2009), a forma como os docentes pensam o uso das TDICs em suas práticas revela como pensam o fazer docente. Professores que optam por aulas expositivas, ao utilizarem as TDICs manterão as estratégias empregadas nesse tipo de metodologia de ensino, como evidenciado na resposta do G1. Sendo assim, o fato de os licenciandos não explicitarem no conceito de docência a necessidade de uso das tecnologias digitais pode denotar que não percebem no fazer docente a importância metodológica do uso desse tipo de tecnologia. No entanto, ao extrapolar esse ideário estritamente vinculado à docência, conseguem ampliar a importância de uso das TDICs enfatizando não só a melhoria do processo de aprendizagem, como também a do ensino, ainda, porém, de forma inespecífica.

\subsection{Desenvolvimento dos MADEs e compreensão sobre Docência e Tecnodocência}

Foram desenvolvidos cinco (5) MADEs pelos próprios licenciandos integrantes dos grupos interdisciplinares, com características próprias, hospedados no site da Tecnodocência no endereço http://tecnodocencia.virtual.ufc.br/made-2019-1/

O G1 desenvolveu um podcast no formato jornalístico fantástico, interconectando o conteúdo de psicologia das cores, pré-história e timbre musical a partir do tema "Universo planetário". O apresentador do programa fictício narra notícias sobre o Planeta de Cores com entrevistas de especialistas e cidadãos do planeta para explicarem a história, a religião e os costumes do lugar, cuja particularidade são as rochas que emitem sons e luz provocando emoções nos moradores do planeta, tornando-os um povo pacífico. Hospedaram o podcast na plataforma SoundCloud para, posteriormente, utilizarem com alunos de Ensino Médio na prática docente, trabalhando de forma interdisciplinar os conteúdos de História, Música e Psicologia.

O G2 desenvolveu slides interativos utilizando o Google Drive trabalhando de forma interdisciplinar os conteúdos de Biologia, Química e Física. Com o tema "Dança em dupla" a proposta foi obter um MADE interativo de tal forma que os alunos pudessem utilizá-lo durante as práticas docentes, posteriormente, inserindo informações por meio da escrita. A partir da visualização de um vídeo ou uma imagem sobre determinados tipos de dança (tango, forró, contemporânea, zouk) os alunos 
são convidados a refletir sobre a relação entre hormônios e emoções liberados durante a dança visualizados a partir de gráficos matemáticos, além de figuras geométricas formadas pelos corpos dançantes durante a ação de forças físicas com explicação de suas construções e especificações.

O G3 desenvolveu um livro-jogo tomando como tema "O Senhor dos Anéis" a partir da abordagem dos conteúdos de Fisiologia Humana, Arte Noveau e Queda Livre, trabalhando de forma interdisciplinar com as áreas de Biologia, Arte e Física. Diante do uso de uma narrativa não-linear, o aluno (jogador) pode utilizar os conteúdos do MADE para dar continuidade à história desenvolvida pelos licenciandos da maneira que lhe for mais conveniente, estudando os conteúdos apresentados e participando da narrativa por meio da inserção de textos em espaços específicos com a utilização do software Twine.

O G4 desenvolveu um vídeo tomando como tema "Folclore Brasileiro" diante da abordagem dos conteúdos de Educação Ambiental, Etnomusicologia e Socialização, trabalhando de forma interdisciplinar com as áreas de Biologia, Música e Sociologia. Diante da apresentação de cenas de festa junina, quadrilhas, interações sociais e da lenda do curupira, o aluno ao assistir o vídeo pode contribuir com seus conhecimentos prévios a respeito dos conteúdos, visualizar as interações entre as diferentes áreas do saber abordadas e desenvolver uma atividade que é apresentada ao final do MADE por meio da criação de uma lenda pautada em uma música de autoria dos próprios alunos, tomando como base uma problemática ambiental.

O G5 abriu um espaço na rede social Instagram tomando como tema "Música" a partir da abordagem dos conteúdos de Anatomia e Fisiologia do Sistema Auditivo, Substantivos em Inglês, Paródia e Corrosão, trabalhando de forma interdisciplinar com as áreas de Biologia, Letras Inglês, Pedagogia e Química. Diante da criação de um perfil na rede social Instagram denominado Tecnomúsica, os integrantes do grupo enviaram postagens acerca do reconhecimento de padrões de músicas na língua inglesa permitindo ao aluno identificar nesses padrões os substantivos da língua inglesa; do processo químico de corrosão das cordas de instrumentos musicais para o reconhecimento das frequências captadas em um aplicativo específico para essa função, promovendo experimentos para a interação com os alunos; da captação de sons em instrumentos como afinadores de violão e sua relação com a captação dos sons pelo ouvido humano; e, do reconhecimento de paródias com o desenvolvimento de paródias próprias dos alunos que poderão ser compartilhadas com outras pessoas diante do perfil disponível na rede social.

Cada grupo de licenciandos, diante da utilização de temáticas que se distanciaram dos conteúdos específicos abordados, conseguiu estabelecer interconexões com os saberes de cada área do conhecimento, de tal forma que cada uma se tornou essencial para a compreensão do todo. Os licenciandos conseguiram mostrar que o diálogo entre os integrantes e as aprendizagens mútuas em prol de um esforço de conjugação dos saberes se torna fundamental para a produção de materiais interdisciplinares, bem como de ações docentes que permitam ao desenvolvedor e ao usuário dos MADEs a participarem ativamente do processo por meio de inovação e criação.

Dessa forma, conforme explicita Japiassu (2006), a interdisciplinaridade pode se tornar um caminho para se repensar a fragmentação dos saberes, por meio do estabelecimento de parcerias entre os atores que trabalham colaborativamente para conectar os diferentes saberes em prol de um projeto único capaz de explicar o cotidiano de forma mais holística e próxima da realidade humana. Sendo assim, é possível perceber que os licenciandos, mesmo sem conceber inicialmente a Docência e a Tecnodocência como uma possibilidade de atuação de mais de um professor ao mesmo tempo, conseguiram demonstrar, no desenvolvimento dos MADEs, possibilidades de atuação conjunta, colaborativa, de aprendizagem mútua e cessão de espaços, corroborando a afirmação de Japiassu (2006) diante da superação de um ideário sobre docência que vem sendo construído durante toda a Educação Básica e na formação do Ensino Superior, caracterizada por Tardif (2002) como aplicacionista dos saberes que foge da realidade a ser vivenciada posteriormente na prática de sala de aula.

Em relação aos aspectos das TDICs, os licenciandos buscaram em seus MADEs o desenvolvimento de ações que permitissem a construção do conhecimento por parte do usuário. Houve, 
nos cinco grupos, a preocupação em elaborar materiais em que os usuários pudessem inserir informações a partir de percepções e pesquisas nos MADEs elaborados a partir do uso de tecnologias digitais on-line ou off-line. Para Andalécio (2009), ao inserir as TDICs na realidade docente, ocorre um processo de construção colaborativa do conhecimento que evidencia um trabalho conjunto não só entre professores, no caso da interdisciplinaridade, mas, sobretudo, de uma parceria que pode ser estabelecida entre professor e aluno, corroborando as perspectivas teóricas de Lima e Loureiro (2019).

Diante do desenvolvimento dos MADEs, os licenciandos vivenciaram experiências de docência utilizando tecnologias digitais de tal forma que se aproximaram mais do conceito que trouxeram de Tecnodocência do que aquele que trouxeram de Docência no questionário de sondagem. No entanto, é possível que a produção dos MADEs tenha contribuído para ressignificar o ideário construído até então pelos licenciandos sobre o que é ser professor e como atuar metodologicamente diante do uso das TDICs na docência. Esse aspecto se evidencia quando os licenciandos dividem a responsabilidade da construção dos MADEs com os usuários, deixando espaços livres e abertos para que os materiais sejam finalizados quando utilizados em sala de aula.

Os MADEs ficam, portanto, receptivos às ideias dos usuários, denotando que os licenciandos cedem espaço, saindo do lugar de detentor exclusivo do saber. Atingiram, portanto, outro patamar de ressignificação da Docência, internalizando o significado de Tecnodocência, diferenciando-se dos resultados apresentados por Lima e Loureiro (2016b) em que, mesmo diante do desenvolvimento de MADEs, os licenciandos se mantiveram com o ideário de docência voltado para a centralização da ação do professor em seus conhecimentos adquiridos.

Considerando-se a perspectiva de Coll (2009) em que o professor pensa o uso das TDICs na docência da mesma forma que pensa sua prática docente, é possível que diante do desenvolvimento dos MADEs os licenciandos estejam construindo o conceito de Tecnodocência com novos elementos capazes de ressignificar, principalmente, o que concebem sobre Docência. Saíram, portanto, de uma compreensão de docência vinculada à centralização do saber na figura do professor, que atua sozinho no comando da sala de aula, com utilização de recursos metodologicamente limitadores, para uma compreensão que expande seus horizontes no sentido da participação do aluno como agente do saber a partir da utilização de recursos que abrem oportunidades para a criação e o desenvolvimento de metodologias diferenciadas de docência.

\section{Considerações finais}

Diante da busca pela análise das formas como os licenciandos da UFC integram as TDICs e Docência ao desenvolver Materiais Autorais Digitais Educacionais (MADEs), no primeiro semestre de 2019, perceberam-se algumas transformações relevantes na relação que estabelecem entre docência, interdisciplinaridade e TDICs.

Com o desenvolvimento dos MADEs foi possível perceber que os licenciandos abriram espaço para a participação dos usuários como coparticipantes da produção quando os MADEs forem aplicados na prática da docência, permitindo que construam o conhecimento dentro das propostas apresentadas. Utilizaram, para isso, diferentes tipos de tecnologias digitais, diante de um trabalho que se apresenta de forma interdisciplinar e tenta se concretizar nesse formato. Saíram, portanto, de uma compreensão de docência voltada para a centralização do saber no professor que atua de forma isolada, mesmo dentro do contexto da Tecnodocência, para uma nova possibilidade de atuação docente que acolhe alunos e professores para o desenvolvimento de um trabalho colaborativo e contextualizado, mais próximo de uma compreensão ampla sobre o fenômeno estudado.

Sendo assim, inovar em metodologias e didáticas que permitam a construção de MADEs por parte de licenciandos em diferentes momentos e espaços dentro do processo formativo inicial pode ser relevante para as formações de licenciandos, tendo em vista que a resposta apresentada pelos grupos 
interdisciplinares foi positiva no sentido de se adaptarem aos desafios apresentados no desenvolvimento dos MADEs, pensando em aulas que contemplem o estudo de mais de um conteúdo formal e fazendo uso das TDICs em diferentes contextos.

Compreende-se que o desenvolvimento de uma pesquisa com um grupo com trinta (30) licenciandos não tem a pretensão de generalizações e se limita a descrever e explicar um fenômeno pontual de um grupo com características específicas. Sendo assim, pretende-se continuar com a pesquisa em semestres subsequentes com alunos que participam da disciplina Tecnodocência, aprofundando os estudos conceituais sobre o tema, bem como sobre a prática da docência interdisciplinar no âmbito escolar, diante do desenvolvimento e da aplicação de MADEs com alunos de escola pública.

\section{Referências}

ALMEIDA, M. E. B. de, \& VALENTE, J. A. (2011). Tecnologias e currículo: trajetórias convergentes on divergentes? São Paulo: Paulus.

ANDALÉCIO, A. M. L. (2009). Informaģão, Conhecimento e Transdisciplinaridade: mudanças na Ciência, na Universidade e na Comunicaşão Cientifica (Tese de doutorado). Escola de Ciência da Informação, Universidade Federal de Minhas Gerais, Belo Horizonte, MG, Brasil.

AUSUBEL, D. P., NOVAK, J. D., \& HANESIAN, H. (1980). Psicologia Educacional. Rio de Janeiro: Interamericana.

BARANAUSKAS, M. C. C., MARTINS, M. C., \& VALENTE, J. A. (Orgs.) (2013). Codesign de Redes Digitais: Tecnologia e Educação a Serviço da Inclusão Social. Porto Alegre: Penso.

CHARLOT, B. (2005). Relaşão com o Saber, Formação dos Professores e Globalização. Porto Alegre: Artmed.

COLL, C. (2009). Aprender y enseñar con las TIC: expectativas, realidad y potencialidades. In R. CARNEIRO, J. C. TOSCANO, \& T. DÍAZ. (Orgs.) Los desafios de las TIC para el cambio educativo (pp. 113126). Madrid, España: Fundación Santillana.

JAPIASSU, H. (2006). O Sonbo Transdisciplinar e as razões da Filosofia. Rio de Janeiro: Imago.

KARSENTI, T., VELLENEUVE, S., \& RABY, C. (2008). O uso pedagógico das Tecnologias da Informação e da Comunicação na Formação dos Futuros Docentes no Quebec. Educ. Soc., 29(104), 865889.

KERCHOVE, D. de. (2009). A Pele da Cultura: investigando a nova realidade eletrônica. São Paulo: Annablume.

LEMOS, A. A (2013). Comunicação das Coisas: teoria ator-rede e cibercultura. São Paulo: Annablume.

LIMA, L., \& LOUREIRO, R. (2016a). A Aprendizagem Significativa do Conceito de Tecnodocência: integração entre Docência e Tecnologias Digitais. Revista Novas Tecnologias na Educação, 14(1), 1-10.

LIMA, L. de, \& LOUREIRO, R. C. (2016b). Integração entre Docência e Tecnologia Digital: o desenvolvimento de Materiais Autorais Digitais Educacionais em contexto interdisciplinar. Revista Tecnologias na Educação, 17(8), 1-11.

LIMA, L. de, \& LOUREIRO, R. C. (2019). Tecnodocência: concepp̧ões teóricas. Fortaleza: Edições UFC.

LOUREIRO, R., LIMA, L. de, \& SOARES, A. (2014, setembro). Docência Universitária no Contexto das Tecnologias Digitais da Informação e Comunicação. Anais do Congreso Internacional de Informática Educativa, Fortaleza, CE, Brasil, 19.

MORAES, R., \& GALIAZZI, M. do C. (2016). Análise Textual Discursiva. Ijuí: Ed. Unijuí, 2016. 
PAPERT, S. (2008). A Máquina das Crianças: repensando a escola na era da informática. Porto Alegre: Artmed. RAMOS, P., \& STRUCHINER, M. (2009). Concepções de Educação em Pesquisas sobre materiais informatizados para o Ensino de Ciências e de Saúde. Ciência \& Educação, 15(3), 659-679.

RICARDO, E. C. (2007). Educação CTSA: Obstáculos e possibilidades para sua implementação no contexto escolar. Ciência \& Ensino, 1(especial), 1-15.

STAKE, R. E. (2010). Investigación con estúdio de casos. Madrid: Morata.

UNESCO. (2002). Information Communication Technology in Education: a curriculum for schools and programme of teacher development. Recuperado de http://unesdoc.unesco.org/images/0012/001295/129538e.pdf.

TARDIF, M. (2002). Saberes docentes e formação profissional. Petrópolis, RJ: Vozes.

YIN, R. K. (2010). Estudo de Caso: planejamento e métodos. Porto Alegre: Bookman.

\section{Sobre os Autores}

\section{LUCIANA DE LIMA}

(iD) ORCID: http://orcid.org/0000-0002-5838-8736

Doutora em Educação, líder do Grupo de Pesquisa Tecnodocência, professora Adjunta do Instituto Universidade Virtual, Universidade Federal do Ceará.

luciana@virtual.ufc.br, https://tecnodocencia.virtual.ufc.br.

\section{ROBSON CARLOS LOUREIRO}

(iD) ORCID: http://orcid.org/0000-0001-7701-3799

Doutor em Educação, membro do Grupo de Pesquisa Tecnodocência, professor Associado do Instituto Universidade Virtual, Universidade Federal do Ceará.

robson@,virtual.ufc.br, https://tecnodocencia.virtual.ufc.br.

\section{BRENA COLLYER DE AGUIAR}

ORCID: https://orcid.org/0000-0002-7096-8565

Mestre em Recursos TIC, membro do Grupo de Pesquisa Tecnodocência, designer instrucional da Universidade de Sussex, Reino Unido.

brenacollyer@gmail.com, https://tecnodocencia.virtual.ufc.br.

Enviado em: 6 Agosto. 2020

Aprovado em: 21 Setembro 2020 